\title{
COMPLICAÇõES RARAS DO LUPUS ERITEMATOSO SISTEMICO: COMPROMETIMENTO DO TRONCO CEREBRAL E HEPATITE
}

\author{
MICHEL P. LISON * \\ Décio MEgA **
}

A raridade do comprometimento do tronco cerebràl como complicação neurológica do lupus eritematoso sistêmico (LES) justifica a apresentação de nova observação. Por sua vez, distúrbios eviđentes de função hepática no decorrer da mesma moléstia constituem objeto de discussão. A ocorrência destas duas complicações na mesma paciente no decorrer da evolução desta colagenose motiva a presente publicação.

\section{OBSERVAÇAO}

A.F., com 24 anos de idade, sexo feminino, branca, procurou o Departamento de Clínica Neurológica em setembro de 1965, queixando-se de formigamentos com distribuição braquiofacial à esquerda precedidos de sensação vertiginosa, desde o dia anterior à consulta. Esses formigamentos também comprometiam a língua do mesmo lado. Logo a seguir, tornou-se evidente uma diminuição da fôrça muscular no membro superior esquerdo. Desde a instalação do quadro a paciente teve dificuldades à deglutição e distúrbios na articulação das palavras. Antecedentes pessoais - Aos 15 anos de idade a paciente apresentou, pela primeira vez, um quadro poliarticular agudo, com caracteres inflamatórios levando à suspeita de febre reumática. Contudo, o aparecimento, meses depois, de lesões eritêmato-descamantes nas regiōes malares e no dorso do nariz, levantou a suspeita de lupus eritematoso agudo, suspeita essa confirmada pelos exames paraclínicos e pela evolução. Mediante tratamento com corticosteróides e antimaláricos, houve melhora da sintomatologia e do estado geral. Entretanto, apesar do uso constante da medicação, ocorreram recidivas que obrigaram a repetidas internações no Serviço de Clínica Médica, até novembro de 1958. Desde entāo a paciente ficou livre de qualquer sintomatologia, dispensando o tratamento anteriormente instituido. Esse estado de cura aparente permaneceu até o dia em que procurou nosso Serviço com as queixas acima referiđas. Exame clínico-neurológico - Por ocasião da admissão, em 2-9-1965, o exame mostrava paciente emagrecida com mucosas descoradas; a temperatura era normal e não havia comprometimento cutâneo e articular. A paciente, deprimida, chorou várias vêzes no decorrer do exame. Pressão arterial 12/8. Paresia flácida braquiofacial à esquerda. Hipoestesia dolorosa na hemilíngua esquerda. Reflexo corneano diminuido à esquerda. Síndrome de Claude Bernard-Horner à esquerda, paresia do

Departamento de Clínica Neurológica da Faculdade de Medicina de Ribeirão Prêto da Universidade de São Paulo (Prof. J. Armbrust-Figueiredo): * Professor Assistente; ** Instrutor. 
palato do lado direito e da hemilíngua esquerda. Fala disártrica. Exames complementares - Hemograma: 3.200 .000 eritrócitos por $\mathrm{mm}^{3} ; 10,9 \mathrm{~g}$ de hemoglobina; 3.500 leucócitos por $\mathrm{mm}^{3}(2 \%$ de neutrófilos bastonetes, $54 \%$ de neutrófilos segmentados, $2 \%$ de eosinófilos, $38 \%$ de linfócitos, $4 \%$ de monócitos). Hemossedimentação: $57 \mathrm{~mm}$ na primeira hora. Exame de urina: proteinúria moderada. No sangue: uréia 36 $\mathrm{mg} \%$; creatinina $1,8 \mathrm{mg} \%$; ácido úrico $6,5 \mathrm{mg} \%$. Radiografia do crânio normal. Eleirencefalograma: irregularidade difusa e bilateral do ritmo cerebral, mais evidente ao nivel das projeções hemisféricas esquerdas, onde havia, igualmente, sinais irritativos traduzidos por frequientes surtos de disritmias paroxísticas com ondas "sharp". Exame de liquido cefalorraqueano normal.

Na enfermaria o quadro evoluiu ràpidamente. Desde os primeiros dias verificou-se hiperreflexia osteotendinosa bicipital, estilo-radial e cúbito-pronadora à esquerda. O sinal de Hoffman apareceu à esquerda. Os distúrbios sensitivos e da fala regrediram em poucos dias e, por ocasiāo da alta, em 15 de setembro, havia regressão da paresia e dos distúrbios por acometimento de nervos cranianos. Depois da alta hospitalar e em poucos dias houve regressão completa do quadro neurológico.

Entretanto, em fins de setembro a paciente apresentou polaquiúria, disúria e hematúria. A cultura de urina revelou o crescimento de Escherichia coli, sendo então administrada Sigmamicina, havendo regressão do quadro urinário. No entanto, o aparecimento de fraqueza geral e anorexia fêz com que a paciente fôsse internada no Serviço de Clínica Médica, onde foi assinalada icterícia moderada e hepatomegalia, sendo confirmada a existência de nefropatia, com proteinúria e hematúria verificadas em exames sucessivos. Pesquisa de células LE pela técnica do coágulo, positiva. Proteinas totais $8,2 \mathrm{~g} / 100 \mathrm{ml}(3,6 \mathrm{~g}$ de albumina e $4,5 \mathrm{~g}$ de globulinas). Transaminase G.O. no plasma, 38 unidades Reitman-Frankel. Bilirrubina direta (1) minuto) $1,7 \mathrm{mg} / 100 \mathrm{ml}$ para bilirrubinemia total de $2,9 \mathrm{mg}$. Testes de floculação: Hanger +++ ; turvação do timol, 12,5 U. Mac Lagan; formol-gel positivo. Eletroforese de proteinas séricas: albumina $3,39 \mathrm{~g} / 100 \mathrm{ml}$; globulina alfa-1 $0,42 \mathrm{~g} \%$; globulina alfa-2 1,1 g\%; globulina beta $0,86 \mathrm{~g} \%$; globulina gama $2,79 \mathrm{~g} \%$.

Uma semana mais tarde a icterícia tinha desaparecido e nôvo exame revelou taxa de bilirrubina total de $1,1 \mathrm{mg}$, com $0,1 \mathrm{mg}$ de bilirrubina direta.

\section{COMENTARIOS}

A ocorrência de manifestações neurológicas no decorrer da evolução do LES tem sido verificada em cêrca de $25 \%$ dos casos ${ }^{6}$. Sinais de comprometimento encefálico são mais comuns, predominando as manifestações convulsivas e mentais, seguindo-se alterações focais e síndrome corêica. Menos freqüente é o comprometimento do sistema nervoso periférico. Menos vêzes, ainda, têm sido relatadas hemorragias meníngeas e meningites assépticas ${ }^{1}$, 3, 4. O comprometimento do tronco cerebral tem sido referido em escasso número de casos. Assim, Kulis e Trakas ${ }^{3}$, ao descreverem um caso próprio em 1965, acreditam ter sido o segundo na literatura em que tal comprometimento foi observado.

Em nossa paciente o comprometimento de vários nervos cranianos e a presença de síndrome de Claude Bernard-Horner sugerem o acometimento do tronco cerebral. Os achados eletrencefalográficos demonstraram, no entanto, que as lesões não se limitavam ao tronco cerebral, desde que exames sucessivos revelaram a presença de disritmia paroxística focal e menor organização do ritmo cerebral ao nivel das projeções do hemisfério esquerdo.

Correspondendo à melhora clínica houve, inicialmente, melhora eletrencefalográfica; porém, nôvo traçado realizado cêrca de um mês depois do 
desaparecimento das manifestações neurológicas, revelou piora do EEG na ausência de achados clínicos objetivos. A êste respeito tem sido salientada a ausência de especificidade das alterações eletrencefalográficas que, freqüentemente, não apresentam correlação com o quadro clínico ${ }^{1}$.

O quadro neurológico em nossa paciente se instalou na ausência de manifestações clínicas gerais de LES, embora os exames subsidiários revelassem de modo persistente a atividade da moléstia. As manifestações neurológicas regrediram de maneira espontânea, sem que qualquer tratamento fôsse instituído. Este caso justifica, portanto, as reservas que devem ser levantadas quanto à eficácia do tratamento hormonal ou, como mais recentemente foi preconizado por Kulis e Trakas ${ }^{3}$, do tratamento heparínico nas complicações neurológicas do LES.

Em nosso caso, após a remissão espontânea do quadro neurológico, surgiram sinais de comprometimento hepático agudo (icterícia, hiperbilirrubinemia, positividade dos testes de Mac Lagan e de Hanger), lembrando os casos relatados por Bartholomew e col. ${ }^{2}$ em mulheres jovens. A extrema raridade do LES com comprometimento hepático severo foi salientada especialmente por Sarrazin ${ }^{5}$ em recente revisão da literatura. Sòmente a evolução permitirá verificar, em nossa doente, se o acometimento hepático agudo e recente será seguido, ou não, por uma hepatite crônica.

\section{RESUMO}

São descritas complicações neurológicas espontâneamente reversiveis envolvendo particularmente o tronco cerebral em mulher de 24 anos de idade portadora de lupus eritematoso sistêmico. Após regressão das manifestações neurológicas clínicas surgiu quadro clínico e laboratorial de disfunção hepática aguda que também regrediu espontâneamente. Os achados clínicos e paraclínicos foram discutidos.

\section{SUMḾMARY}

Rare complications of systemic lupus erythematosus: involvement of the brainstem and hepatitis

A case of systemic lupus erythematosus complicated by involvement of the brainstem is reported. The patient, a 24 years old white female, presented left brachio-facial paresthesis and paresis, difficulty to swallow, dysarthria, Horner's syndrome and hypoesthesia of the tongue. The EEG showed focal changes on the left side. The clinical signs improved spontaneously but the EEG record persisted abnormal. Following the neurological improvement, the patient showed signs of liver dysfunction which disappeared spontaneously after several days. The clinical and laboratorial findings are discussed. 


\section{REFERENCIAS}

1. AITA, J. A. - Neurologic Manifestations of General Diseases. Charles C. Thomas, Springfield (Illinois), 1964, pp. 176-223. 2. BARTHOLOMEW, L. G.; HAGEDORN, A. B.; CAIN, J. C. \& BAGGENSTOSS, A. H. - Hepatitis and cirrhosis in women with positive clot tests for lupus erythematosus. New Engl. J. Med. 259: 947-956, 1958. 3. KULIS, J. C. \& TRAKAS, D. A. - Systemic lupus erythematosus with brainstem involvement. Neurology 15:878-879, 1965. 4. LAPRESLE, J. - Les manifestations neuropsychiatriques du lupus érythémateux disséminé. Sem. Hôp. Paris 38:36-39, 1962. 5. SARRAZIN, A. - L'“hépatite lupoide" et l'hépatite lupique existent-elles? Sem. Hôp. Paris 38:33-38, 1962. 6. SIEKERT, R. E. \& CLARK, E. C. - Neurologic signs and symptoms as early manifestations of systemic lupus erythematosus. Neurology 5:84-88, 1955.

Departamento de Neurologia - Faculdade de Medicina de Ribeirão Prêto - Ribeirão Prêto, SP - Brasil. 